\title{
Spectrophotometric determination of palladium using 2-hydraziniopyridine
}

\author{
Ahmed Ahmed Soliman a,*, Sattar Rajab Majeed a,b and Fawzy Ali Attaby a \\ a Department of Chemistry, Faculty of Science, Cairo University, 12613 Giza, Egypt \\ b Department of Chemistry, Faculty of Science, Al-Anbar University, 31001 Al-Ramady, Iraq \\ ${ }^{*}$ Corresponding author at: Department of Chemistry, Faculty of Science, Cairo University, 12613 Giza, Egypt. \\ Tel.: +2.0111.0121379. Fax: +2.02.35727556. E-mail address: ahmedsoliman61@gmail.com (A.A. Soliman).
}

\section{ARTICLE INFORMATION}

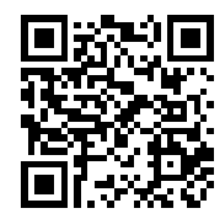

DOI: $10.5155 /$ eurjchem.5.1.150-154.926

Received: 11 September 2013

Received in revised form: 26 October 2013

Accepted: 05 November 2013

Online: 31 March 2014

\section{KEYWORDS}

Palladium

Stoichiometry

Stability complexes

2-Hydraziniopyridine

Validation parameters

Spectrophotometric determination

\section{Introduction}

Palladium (Pd) is one of the platinum group elements (PGEs) and it is present on the earth crust (EC) at very low concentrations. Since the introduction of catalytic converters, a constant increase of noble metals demand for application in auto catalysts has been observed [1-3]. The problems in the determination of trace Pd in environmental, biological samples are the very low concentrations and lack of appropriate certified reference materials (CRMs) for validation of the methods [1]. The determination of palladium using many techniques encountered many complications such as the irreversibility of the electrode processes [4], using electrochemical methods, working at the nuclear reactor facility and using short irradiation and cooling times using neutron activation analysis, interferences from a lot of elements using inductively coupled plasma mass spectrometry [5-7]. Therefore in most cases separation and preconcentration methods are developed before measurement $[6,8]$. Hence, the spectrophotometric methods can compete and be more advantageous in respect of simplicity and low operating costs. A wide variety of spectrophotometric reagent, such as 2-arylthio-p-nitroacetophenone [9] and 2-(2-quino lylazo)-5-diethylaminobenzoic acid [10], 2-(5-bromo-2-pyridyl azo)-5-diethylaminophenol [11], 2-(2-benzothiazolylazo)-5dimethylamino-4-tolylarsonic acid [12], 1-(2-quino lylazo)2,4,5-trihydroxybenzen (QATB) [13], 2-hydroxy-5-methylaceto phenoneisonicotinoylhydrazone (HMAINH) [14] and benzilthio semicarbazide [15] are used as reagent for spectrophotometric determination of $\mathrm{Pd}(\mathrm{II})$ ion. On the other hand, pyridylamines find a large application in the field of coordination and analytical chemistry with different metal ions due to their potential biological, spin transition, organometallic and catalytic activities [16-19]. Among others, 2-hydrazinopyridine (hzpy) is an extremely potential ligand for complex formation with metal ions.

We reported the detailed kinetic and mechanistic study for the complex formation reactions of 2-hydrazinopyridine with $\mathrm{Fe}(\mathrm{II}), \mathrm{Fe}(\mathrm{III})$ [20] and Pd(II) [21]. In this study, a new simple, sensitive and low cost method for the determination of palladium (II) using 2-hydrazinopyridine (hzpy) (Scheme 1) is presented [22,23].<smiles>NNc1ccccn1</smiles>

2-Hydrazinylpyridine (hzpy)

Scheme 1 


\section{Experimental}

\subsection{Apparatus}

Spectrophotometric measurements were performed on a UV-visible optizem double beam spectrophotometer, Taiwan using matched $10 \mathrm{~mm}$ quartz cells. The $\mathrm{pH}$ measurements were carried using 3310-JENWAY pH-meter, calibrated with standard buffer solutions.

\subsection{Reagents}

Sodium tetrachloropalladate and 2-hydrazinopyridine hydrochloride were supplied by Aldrich. All solvents were of analytical grade and were purified by distillation before used. Double-distilled water was used throughout the study.

\subsection{Preparation of standard solutions}

A standard $1.0 \times 10^{-3} \mathrm{M}$ palladium (II) solution was prepared by dissolving $0.00735 \mathrm{~g}$ in $25 \mathrm{~mL}$ distilled water. Phosphate buffer solutions of varying $\mathrm{pH}(2-10)$ were prepared by mixing appropriate volumes of $0.1 \mathrm{M}$ potassium dihydrogen phosphate with $0.1 \mathrm{M}$ sodium hydroxide. A standard solution of 2hydraziniopyridine hydrochloride $\left(1.0 \times 10^{-3} \mathrm{M}\right)$ was prepared by dissolving $0.0045 \mathrm{~g}$ of pure substance in $25 \mathrm{~mL}$ distilled water.

\subsection{Effect of diverse ion}

The effect of the various foreign ions were investigated by mixing $0.5 \mathrm{~mL}$ of $1 \times 10^{-3} \mathrm{M} \mathrm{Pd}(\mathrm{II})$ and $1.0 \mathrm{~mL}$ of $1 \times 10^{-3} \mathrm{M}$ with 5 , $10,15,20,25,30$ folds $(\mu \mathrm{g} / \mathrm{mL})$ of $\mathrm{Co}(\mathrm{II}), \mathrm{Ni}(\mathrm{II}), \mathrm{Cu}(\mathrm{II}, \mathrm{Zn}(\mathrm{II})$ and $V(V)$ and with $50,100,150$ folds $(\mu \mathrm{g} / \mathrm{mL})$ of citrate, acetate and borate.

\section{Results and discussion}

\subsection{Absorption spectrum of palladium-hzpy complex}

Three solutions of $0.5 \mathrm{~mL}$ of $1 \times 10^{-3} \mathrm{M}$ Pd(II) (1), $1.0 \mathrm{~mL}$ of $1 \times 10^{-3} \mathrm{M}$ hzpy (2) and their mixture $\left(0.5 \mathrm{~mL}\right.$ of $1 \times 10^{-3} \mathrm{M} \mathrm{Pd}(\mathrm{II})$ and $1.0 \mathrm{~mL}$ of $1 \times 10^{-3} \mathrm{M}$ hzpy) (3) diluted to $10 \mathrm{~mL}$ in $10 \mathrm{~mL}$ volumetric flask with double distilled water was prepared. The absorbance of solutions $\mathbf{1}$ and $\mathbf{2}$ were measured against double distilled water while the absorbance of solution $\mathbf{3}$ was measured against solution 2 in the wavelength range of 200 $800 \mathrm{~nm}$. The complex exhibited the absorption maximum at $510 \mathrm{~nm}$ (Figure 1), the molar absorptivity of complex calculated from the absorbance data was found to be $2.973 \times 10^{3}$ $\mathrm{L} / \mathrm{mol} . \mathrm{cm}$ at $510 \mathrm{~nm}$.

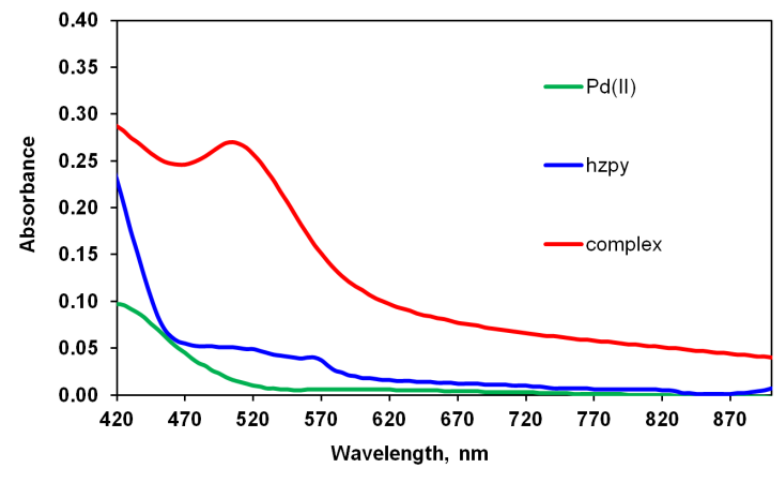

Figure 1. Absorption spectra of palladium(II), hzpy and Pd(II)-hzpy complex solution.

\subsection{Effect of $\mathrm{pH}$}

The effect of $\mathrm{pH}$ on the determination of palladium (II) in aqueous solution medium was investigated over a $\mathrm{pH}$ range 210. For this purpose, solutions containing $0.5 \mathrm{~mL}$ of $1 \times 10^{-3} \mathrm{M}$ Pd(II) and $1.0 \mathrm{~mL}$ of $1 \times 10^{-3} \mathrm{M}$ hzpy diluted to $10 \mathrm{~mL}$ with phosphate buffer solutions of variable $\mathrm{pH}$ (2-10). The absorbance of these solutions was measured at $510 \mathrm{~nm}$ against $1.0 \mathrm{~mL}$ of $1 \times 10^{-3} \mathrm{M}$ hzpy diluted with phosphate buffer of the same $\mathrm{pH}$ value as the solutions. As it is clearly seen from Figure 2 , the amount of palladium can quantitatively be determined at $\mathrm{pH}=6.0-6.5$.

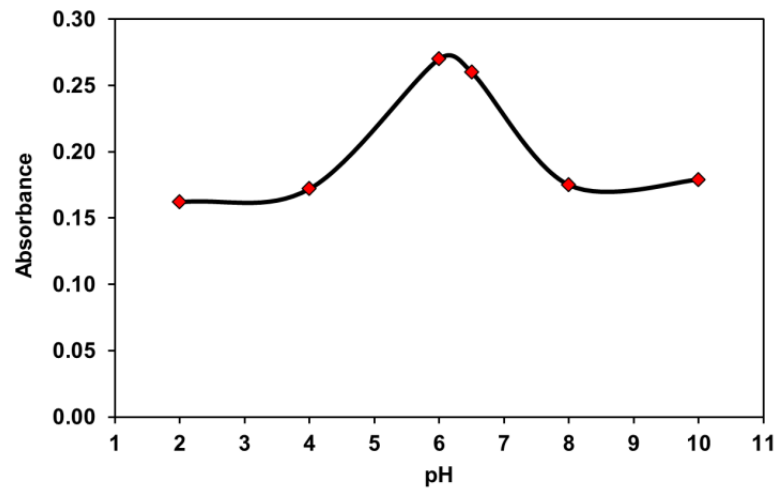

Figure 2. Effect of $\mathrm{pH}$ on the formation of palladium(II)-hzpy complex.

\subsection{Effect of time on the formation of Pd(II)-hzpy complex}

The effect of time on the stability of the complex formation was studied by following the absorbance of the complex solution at different time intervals. It was found that the absorbance remains almost constant for $24 \mathrm{~h}$. This allows the processing of large batches of samples and increases the reliability of the method. The result is shown in Figure 3.

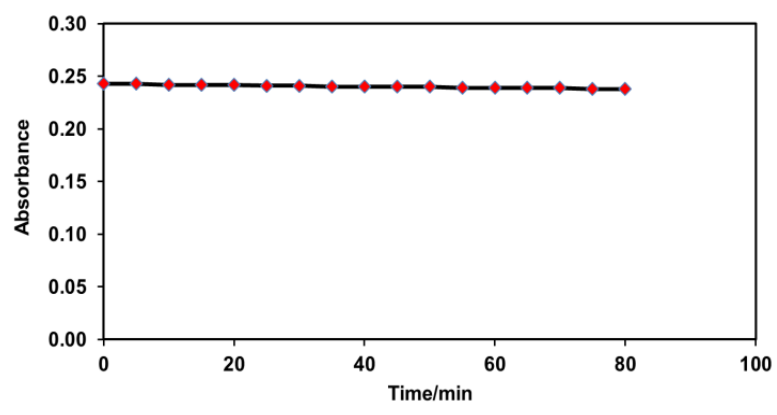

Figure 3. Effect time on the formation of Pd-hzpy complex.

\subsection{Effect of hzpy concentration}

The effect of reagent concentration was studied by varying hzpy concentration; $0.1 \mathrm{~mL}\left(1 \times 10^{-5} \mathrm{M}\right)$ to $2.0 \mathrm{~mL}\left(2.0 \times 10^{-4} \mathrm{M}\right)$ mixed with constant $\mathrm{Pd}(\mathrm{II})$ concentration $0.5 \mathrm{~mL}\left(5.0 \times 10^{-5} \mathrm{M}\right)$ and measured at $510 \mathrm{~nm}$ and at $\mathrm{pH}=6.0-6.5$ (Mole ratio method; vide infra). It has been found that $0.5 \mathrm{~mL}$ of hzpy $\left(5.0 \times 10^{-5} \mathrm{M}\right)$ brought about the maximum absorbance. For higher concentrations, the absorbance had slight change, therefore $1.0 \mathrm{~mL}$ of $1 \times 10^{-3} \mathrm{M}$ hzpy has been recommended in the application. 


\subsection{Effect of diverse ion}

The effect of the various foreign ions was investigated in order to find tolerance limit of these ions in the extraction of $\operatorname{Pd}(\mathrm{II})$. No interference was observed in the presence of following ions at the amounts $(\mu \mathrm{g} / \mathrm{mL})$ shown in brackets, as Co(II) (20) Ni(II) (25), Cu(II) (15), Zn(II) (30), V(V) (20), citrate $(100)$, acetate $(100)$, borate $(100)$.

\subsection{The stoichiometry and stability of Pd-hzpy complex}

\subsubsection{Job's method of continuous variations}

The job's method of continuous variation was applied as described by Yoe and Jones $[24,25]$. Keeping the sum of the molar concentration of $\mathrm{Pd}(\mathrm{II})$ and hzpy constant, the ratio of both $\operatorname{Pd}(\mathrm{II})$ and hzpy was varied and the absorbance of the resultant mixtures were recorded at $510 \mathrm{~nm}$ and $\mathrm{pH}=6.0-6.5$ (Table 1). The maximum absorbance corresponds to the stoichiometric ratio, this was found at 1:1 (Pd(II): hzpy).

Table 1. Job's method of continuous variation data of palladium(II)-hzpy complex.

\begin{tabular}{lllll}
\hline Series & $\begin{array}{l}\text { Metal conc. } \\
\left(\times \mathbf{1 0}^{-4} \text { moles }\right)\end{array}$ & $\begin{array}{l}\text { Ligand conc. } \\
\left(\times \mathbf{1 0}^{-4} \mathbf{~ m o l e s}\right)\end{array}$ & $\begin{array}{l}\text { Mole } \\
\text { fraction }\end{array}$ & $\begin{array}{l}\text { Absorbance at } \\
\mathbf{5 1 0} \mathbf{~ n m}\end{array}$ \\
\hline 1 & 0.0 & 1.0 & 0.0 & 0.030 \\
2 & 0.2 & 0.8 & 0.2 & 0.077 \\
3 & 0.4 & 0.6 & 0.4 & 0.166 \\
4 & 0.5 & 0.5 & 0.5 & 0.183 \\
5 & 0.6 & 0.4 & 0.6 & 0.177 \\
6 & 0.8 & 0.2 & 0.8 & 0.119 \\
7 & 1.0 & 0.0 & 1.0 & 0.065 \\
\hline
\end{tabular}

The stability constant of the Pd-hzpy complex was evaluated from the Job's method of various variations using the following equations [26-29].

$K_{f}=\frac{[M L]}{[M] \cdot[L]}$

$K_{f}=\frac{\left[\frac{A_{2}}{A_{1}}\right]}{\left[1-\frac{A_{2}}{A_{1}}\right]\left[C L-C M\left(\frac{A_{2}}{A_{1}}\right)\right]}$

where, $\mathrm{A}_{1}=$ absorbance at break point, $\mathrm{A}_{2}=$ actual absorbance, $\mathrm{C}_{\mathrm{M}}=$ concentration of metal, and $\mathrm{C}_{\mathrm{L}}=$ concentration of ligand at equilibrium.

\subsubsection{Mole ratio method}

The stoichiometric ratio was also evaluated using the mole ratio method [30] in which varying (hzpy) concentrations $\left(2 \times 10^{-5}\right.$ to $\left.2.0 \times 10^{-4} \mathrm{M}\right)$ was mixed with constant $\mathrm{Pd}(\mathrm{II})$ concentration $\left(5.0 \times 10^{-5} \mathrm{M}\right)$ and at $510 \mathrm{~nm}$ and at $\mathrm{pH}=6.0-6.5$ (Table 2), a sharp break was observed at 1:1 mole ratio of hzpy and Pd(II).

Table 2. Mole Ratio data of palladium (II)-hzpy complex.

\begin{tabular}{llll}
\hline Series & Ligand $(\boldsymbol{\mu g} / \mathbf{m L})$ & {$[\mathbf{L}] /[\mathrm{M}]$} & Absorbance at $\mathbf{5 1 0} \mathbf{~ n m}$ \\
\hline 1 & 1.42 & 0.267925 & 0.097 \\
2 & 2.84 & 0.535849 & 0.152 \\
3 & 5.68 & 1.071698 & 0.223 \\
4 & 8.52 & 1.607547 & 0.221 \\
5 & 11.36 & 2.143396 & 0.229 \\
6 & 14.20 & 2.679245 & 0.236 \\
7 & 17.04 & 3.215094 & 0.241 \\
8 & 19.88 & 3.750943 & 0.242 \\
9 & 22.72 & 4.286792 & 0.238 \\
10 & 25.56 & 4.822642 & 0.239 \\
\hline
\end{tabular}

The stability constant was evaluated by Benesi-Hildebrand equation [31]. The corresponding equation for mole ratio method is as follows:
$\frac{[P d]}{A}=\frac{1}{\varepsilon}+\left(\frac{1}{(K \cdot \varepsilon}\right) \frac{1}{[L]}$

where $[\mathrm{Pd}]$ and $[\mathrm{L}]$ are the total concentration of palladium and hzpy; respectively, A and $\varepsilon$ are the absorbance and the molar absorptivity of the complex at $510 \mathrm{~nm}$, and $\mathrm{K}$ is the stability constant of the complex. On plotting the values of [Pd]/A versus $1 /[\mathrm{L}]$, a straight line was obtained (Figure 4) with slope equals $(1 / K . \varepsilon)$ and intercept of this line with the ordinate is $(1 / \varepsilon)[32]$

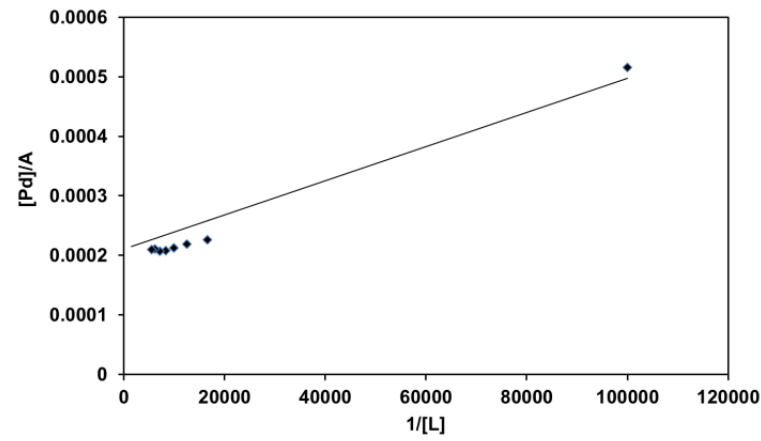

Figure 4. Benesi-Hildebrand plot of palladium (II)-hzpy complex.

\subsection{Validity of the method}

\subsubsection{Determination of linear range}

$2.0 \mathrm{~mL}$ of $1.0 \times 10^{-3} \mathrm{M}$ hzpy was pipetted into each of ten 10 $\mathrm{mL}$ volumetric flask containing $0.1,0.2,0.3,0.4,0.5,0.6,0.7,0.8$, $0.9,1.0 \mathrm{~mL}$ of $\mathrm{Pd}(\mathrm{II})\left(1.0 \times 10^{-3} \mathrm{M}\right)$. The solutions were made up to $10.00 \mathrm{~mL}$ by phosphate buffer solution of $\mathrm{pH}=6.0-6.5$. The absorbance of the solutions were measured at $760 \mathrm{~nm}$ and plotted against $\mathrm{Pd}(\mathrm{II})$ concentration in $\mu \mathrm{g} / \mathrm{mL}$, Figure 5 (Table $3)$.

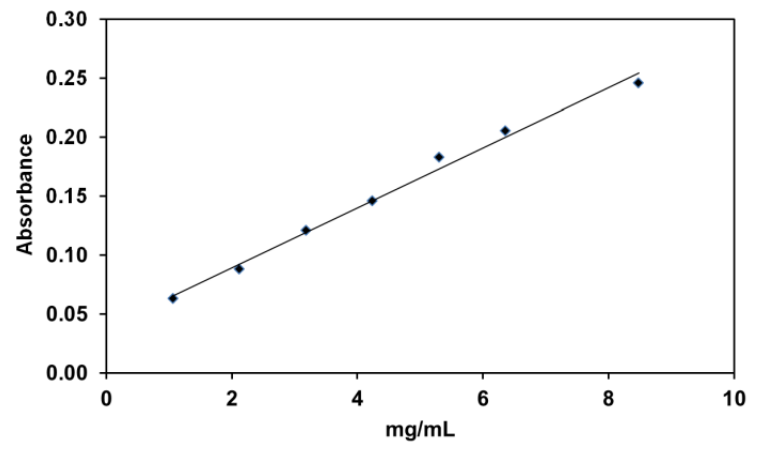

Figure 5. Linearity plot of $\mathrm{Pd}(\mathrm{II})-\mathrm{hzpy}$ complex at $510 \mathrm{~nm}$ and $\mathrm{pH}=6.0-6.5$.

\subsubsection{Sensitivity of the method}

The sensitivity of the method was tested by evaluation of both the limit of detection (LOD), limit of quantification (LOQ) and Sandell's sensitivity $[26,33]$.

The limit of detection (LOD) is the lowest amount of the investigated compound in a sample that can be detected, but not necessarily quantified with an acceptable uncertainly. LOD of a method is an important factor if quantitative measurements are to be made at concentrations close to it [26] LOD was calculated from the calibration graph of the Pd(II)hzpy system where the intercept $\left(\mathrm{y}_{\mathrm{B}}\right)$ can be calculated. The following equations were used: 
Table 3. Analytical parameters using hzpy-reagent.

\begin{tabular}{|c|c|c|c|c|c|c|c|}
\hline Parameter & Value & Ref. [10] & Ref. [11] & Ref. [13] & Ref. [14] & Ref. [15] & Ref. [34] \\
\hline$\lambda_{\max }, \mathrm{nm}$ & 510 & 625 & 550 & 620 & 385 & 338 & 345 \\
\hline Linear range $(\mu \mathrm{g} / \mathrm{mL})$ & $1.06-9.00$ & $0.01-0.60$ & $0.1-2.0$ & $1.6-8.5$ & $2.0-9.0$ & & $7.0-84.0$ \\
\hline Molar absorptivity (L/mol.cm) & $2.973 \times 10^{3}$ & $15.1 \times 10^{4}$ & $9.57 \times 10^{4}$ & $1.25 \times 10^{4}$ & $5.320 \times 10^{3}$ & $0.77 \times 10^{3}$ & $2.05 \times 10^{4}$ \\
\hline Limit of detection $(\mu \mathrm{g} / \mathrm{mL})$ & 0.074 & & $0.021^{*}$ & & & & \\
\hline Limit of quantification $(\mu \mathrm{g} / \mathrm{mL})$ & 0.16 & & & & & & \\
\hline pH range & $6.0-6.5$ & $0.5-2.5$ & 4.5 & $3.0-5.5$ & & 4.0 & \\
\hline 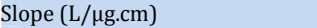 & 0.028 & & 0.060 & & & & \\
\hline Intercept & 0.023 & & -0.0007 & & & & \\
\hline Correlation Coefficient & 0.99 & 0.9995 & 1.0 & & & & \\
\hline Sandell's Sensitivity $\left(\mu \mathrm{g} / \mathrm{cm}^{2}\right)$ & 0.035 & & 0.0112 & 0.0085 & 0.02 & 0.0061 & 0.0052 \\
\hline Stability constant & $7.13 \times 10^{4}$ & & & & & $4.55 \times 10^{7}$ & \\
\hline $\log K$ & 6.40 & & & & & & \\
\hline$\%$ RSD & $0.04-0.41$ & $1.4-2.6$ & 1.62 & & 0.8755 & & 0.53 \\
\hline \% Recovery & $96.61-102.5$ & $93-102$ & $99.5 \pm 0.1$ & & & & \\
\hline
\end{tabular}

* LOD has been taken as $2 \sigma$

Table 4. Accuracy and precision (intra- and inter day)of the spectrophotomtric determination of palladium with 2-hydrazinopyridine (hzpy).

\begin{tabular}{|c|c|c|c|c|c|c|c|c|c|}
\hline \multicolumn{2}{|c|}{ Complex sample } & \multicolumn{4}{|l|}{ Intra-day } & \multicolumn{4}{|l|}{ Inter-day } \\
\hline No & Taken $(\mu \mathrm{g})$ & Found $(\mu \mathrm{g})$ & Recovery (\%) & SD & \%RSD & Found $(\mu \mathrm{g})$ & Recovery (\%) & SD & $\%$ RSD \\
\hline 1 & 1.06 & 1.04 & 98.70 & 0.0023 & 0.220 & 1.049 & 99.04 & 0.004 & 0.411 \\
\hline 2 & 3.18 & 3.2 & 102.06 & 0.0025 & 0.079 & 3.26 & 102.58 & 0.010 & 0.315 \\
\hline 3 & 6.36 & 6.14 & 96.61 & 0.0100 & 0.162 & 6.28 & 98.76 & 0.014 & 0.224 \\
\hline 4 & 8.48 & 8.20 & 97.08 & 0.0035 & 0.04 & 8.31 & 98.06 & 0.023 & 0.286 \\
\hline \multicolumn{2}{|c|}{ Average } & & 98.6125 & 0.004575 & 0.12525 & & 99.61 & 0.01275 & 0.309 \\
\hline
\end{tabular}

$S D=\frac{\sqrt{\left(\sum[y i-\hat{y}]^{2}\right)}}{n-2}$

$\mathrm{LOD}_{\mathrm{abs}}=\mathrm{yв}+3 \mathrm{SD}$

LODabs was transferred to LOD value by the equation of the regression line.

$\mathrm{LOD}_{\mathrm{abs}}=$ slope $(\mathrm{LOD})+\mathrm{y}$

where yi and $\hat{y}$ are the measured absorbance and the absorbance from the regression equation; respectively. SD is the standard deviation of absorbance from the regression line (Equation 4), $\mathrm{LOD}_{\mathrm{abs}}$ is the limit of detection of the absorbance, $\mathrm{y}_{\mathrm{B}}$ is the intercept of the calibration line and LOD is the detection limit expressed in concentration unit.

The limit of quantification (LOQ) is the lowest concentration of compound that can be measured in a sample matrix at an acceptable level of accuracy and precision. The LOQ is generally useful parameter than LOD. The LOQ is relevant only in trace analytical methods when measurements are being at concentrations close to that limit. The LOQ is always higher than the LOD and is often taken as fixed multiple of the LOD (usually double times higher than LOD value). The LOQ is determined by the same way as LOD:

$\mathrm{LOQ}=\mathrm{yB}+10 \mathrm{SD}$

or calculated directly from the LOD [18]:

$\mathrm{LOQ}=3.3 \times \mathrm{LOD}$

Sensitivity of the proposed methods is also determined by calculating Sandell's sensitivity ( $\mu \mathrm{g} / \mathrm{cm}^{2} / 0.001$ Abs unit), which can be defined as the smallest weight of substance that can be detected in column of unit cross section [18]. The values of LOD, LOQ and Sandell's sensitivity are given in Table 3.

\subsubsection{Accuracy and precision}

Accuracy is the main requirement of the determination methods. It can be described as the closeness of agreement between the value that adopted, either as a conventional, true or accepted reference value and the value found. The accuracy in this study is represented and determined by recovery studies. Accuracy of the method is indicated by the closeness of the $100 \%$ recovery value $[26,33]$. The \% recovery ((Found/ Taken) $\times 100$ ) was evaluated to indicate the accuracy of the proposed method.

On the other hand, precision is described as the degree of agreement among individual test results when the procedure is applied repeatedly to multiple samplings of homogeneous sample [26]. The repeatability (intra-day) and reproducibility precision (inter-day) were applied to the proposed method to indicate the precision. Repeatability were performed by analyzing four synthetic Pd(II) samples whose concentrations cover the linear range of the method, each was repeatedly measured 6 times in the same day (intra-day). The reproducibility is tested by the same way as the repeatability but the measurements were performed over two weeks (interday) [18]. All the results are reported as the RSD\% values as indication of the precision. The values calculated for accuracy and precision are given in Table 4.

\subsection{Analytical features}

The purple color Pd(II)-hzpy complex obeyed Beer's law in the concentration range $1.0-9.0 \mu \mathrm{g} / \mathrm{mL}$ (Figure 5). The linearity of calibration graphs was proved by the high values of the correlation coefficient $\left(r^{2}=0.99\right)$ and the small value of the intercept (0.023). The apparent molar absorptivity of the Pd(II)-hzpy complex at $510 \mathrm{~nm}$ was evaluated $\left(2.973 \times 10^{3}\right.$ $\mathrm{L} / \mathrm{mol} . \mathrm{cm}$ ). Sandell's sensitivity value, as calculated from Beer's law data, was found to be $0.0355 \mu \mathrm{g} / \mathrm{cm}^{2}$. The relative standard deviation value was found in the range $0.04-0.41 \%$ and the recovery\% was found in the range 96.61-102.58 for intra-day and inter-day measurements. The limit of detection (LOD) and the limit of quantification (LOQ) were evaluated to be 0.0744 $\mu \mathrm{g} / \mathrm{mL}$ and $0.16 \mu \mathrm{g} / \mathrm{mL}$; respectively (Table 3 and 4). The method was compared with other spectrophotometric methods for the determination of $\mathrm{Pd}(\mathrm{II})$ using other reagents (Table 3). It is obvious from Table 3 that our method is comparable with the given examples [10,11,13-15,34] and being more advantageous with respect to linear range, precision (RSD\%) and accuracy (\%recovery).

\subsection{Recommended method of determination}

Pipette a $1.0 \mathrm{~mL}$ of hzpy solution $\left(1.0 \times 10^{-3} \mathrm{M}\right)$ into different aliquots (1.06-9.00 $\mu \mathrm{g} / \mathrm{mL})$ of $\mathrm{Pd}(\mathrm{II})$ in $10 \mathrm{~mL}$ volumetric flask complete the volume to $10.0 \mathrm{~mL}$ by phosphate buffer $(\mathrm{pH}=6.0$ 6.5). The absorbance of the formed colored-complex is 
measured at $510 \mathrm{~nm}$. The concentration of $\mathrm{Pd}(\mathrm{II})$ in $\mu \mathrm{g} / \mathrm{mL}$ can be calculated from the linear equation $A=0.028 \times C+0.023$.

\section{Conclusion}

The proposed method for determination of Pd(II) using 2hydrazinopyridine hydrochloride has higher sensitivity, high percentage of recovery, wide application range, low relative standard deviation, and they do not need expensive sophisticated apparatus. Furthermore, all the analytical reagents are inexpensive, have excellent shelf life, and are available in many analytical laboratories. Therefore, the method is practical and valuable for routine application in quality control laboratories for analysis and determination of Palladium. The results showed that palladium-2hydraziniopyridine complex, has the highest molar absorptivity value $\left(2.92 \times 10^{3} \mathrm{~L} / \mathrm{mol} . \mathrm{cm}\right)$ and lower detection limit 0.070 $\mu \mathrm{g} / \mathrm{mL}$.

\section{References}

[1]. Angelone, M.; Nadri, E.; Pinto, V.; Cremisini Palladium Emissions in the Environment (review chapter) Springer-Verlag Berlin Heidelberg 2006.

[2]. WHO, Environmental health criteria 226: palladium. International program on chemical safety, World Health Organization (2002), Geneva Johnson Matthey (2001).

[3]. Ravindra, K.; Bencs, L.; Van Grieken, R. Sci. Total Environ. 2004, 318, $1-43$.

[4]. Georgieva, M.; Pilar, B. Fresenius J. Anal. Chem. 1997, 357, 847-880

[5]. Kollensperger, G.; Hann, S.; Stingeder, G. J. Anal. At. Spectrom. 2000 15, 1553-1557.

[6]. Bencs, L.; Ravindra, K.; Van Grieken, R. Spectrochim. Acta B 2003, 58, 1723-1755.

[7]. Fritsche, J.; Meisel, T. Sci. Total Environ. 2004, 325, 145-154.

[8]. Schuster, M.; Schwarzer, M. Anal. Chim. Acta 1996, 328, 1-11.

[9]. Gojare, P. T.; Gaikwad, S. H.; Anuse, M. A. Reserch J. Chem. Envir. 2001, 5(3), 51-56.

[10]. Huang, Z.; Wei, Q.; Yang, X.; Hu, Q.; Chen, J.; Yang, G. Bull. Korean Chem. Soc. 2005, 26(10), 1623-1626.

[11]. Ratre, P.; Kumar, D. Int. J. Emerg. Tech. Comput. Appl. Sci. 2013, 5(4), 421-429.

[12]. Po, B. L.; Hengchuan, L. Talanta 1991, 38(10), 1143-1146.

[13]. Kadyan, P. S.; Singh, D.; Sharma, A.; Singh, I. Der Pharma Chemica 2011, 3 (6), 70-74.

[14]. Pethe G. B.; Bhadange, S. G.; Joshi, M. D.; Aswar, A. S. Adv. Appl. Sci. Res. 2010, 1(2), 58-64.

[15]. Borhade, S. Life sciences Leaflets 2012, 10, 1-9

[16]. Müller, C.; Dumas, C.; Hoffmann, U.; Schubiger, P. A.; Schibli, A. J. Organomet. Chem. 2004, 689, 4712-4721.

[17]. Machuqueiro, M.; Darbre, T. J. Inorg. Biochem. 2003, 94, 193-196.

[18]. Gultneh, Y.; Khan, A. R.; Blaise, D.; Chaudhry, S.; Ahvazi, B.; Marvey, B. B.; Butcher, R. J. J. Inorg. Biochem. 1999, 75, 7-18.

[19]. Soliman, A. A.; Khattab, M. M.; Ramadan, R. M. Trans. Met. Chem. 2007, 32, 325-331.

[20]. Soliman, A. A.; Khattab, M. M.; Linert W. J. Coord. Chem. 2008, 61(13), 2017-2031.

[21]. Khattab, M. M.; Soliman, A. A.; and Linert, W. Int. J. Chem. Kinet. 2010, 42, 132-142.

[22]. Baranska, M.; Lasocha, W.; Kozlowski, H; Soliman, L. M. J. Inorg. Biochem. 2004, 98, 995-1001.

[23]. Beaulieu, N.; Graham, S. J.; Sears, R. W.; Lovering, E. G. J. Pharmaceut. Biomed. 1989, 7, 1705-1709.

[24]. Job, P. Ann. Chim. 1936, 6, 97-144.

[25]. Yoe, J. H.; Jones, A. L. Ind. End. Chem. Anal. 1944, 16, 111-115.

[26]. Miller J. N.; Miller, J. C. Statistics and Chemometrics for Analytical Chemistry, $6^{\text {th }}$ ed., Prentice Hall, England, 2006.

[27]. Tirmizi, S. A.; Muhammad H. S.; Wattoo, S. S.; Waheed. A. Arab. J. Sci. Eng. 2009, 34(2), 43-48.

[28]. Inczedy, J. Analytical Application of Complex Equilibra, John Wiley, Budapest, 1976.

[29]. Thipyapong, K. ; Suksai, C. B. Korean Chem. Soc. 2003, 24(12), $1767-$ 1770

[30]. Ramadan, A.; Mandil, H.; Dahhan, M. Int. J. Pharm. Pharm. Sci. 2012, 5(1), 428-433.

[31]. Benesi, H. A.; Hildebrand, J. H. J. Am. Chem. Soc. 1949, 71, 2703-2707.

[32]. Issa, Y. M.; El-Hawary, W. F.; Yousef, A. F. A.; Senosy, A. R. Spectrochim. Acta A 2010, 75(4), 1297-1303.

[33]. Gouda, A. A.; El-sheikh, R.; El Shafey, Z.; Hossny, N.; El-Azzazy, R. Int. J. Biomde. Sci. 2008, 4(4), 294-302.

[34]. Kumar, A. Anal. Sci. 1995, 11, 281-284. 